\title{
A Domain Specific Innovativeness Perspective Of Student Enrollment In New Major Offerings
}

Joseph O’Donnell, (Email: odonnelj@canisius.edu), Canisius College, Paul Sauer, (Email: sauer@canisius.edu), Canisius College

\begin{abstract}
Colleges and universities have embraced educational innovation as a way to meet needs of students and provide flexibility in delivery of course content. Innovation includes launching new majors such as Digital Media Arts and Accounting Information Systems. Successful new majors must attract students to sustain the major and build a critical mass of students. Schools have often spent little time and effort on marketing new majors and targeting prospective students for the new major. It would be useful for schools to identify prospective students who are innovators, and more likely to enroll in new majors. Prior research on adoption of educational innovations has focused on the educators accepting and implementing new approaches. There is a paucity of research on students' adoption of educational innovations. This study addresses this gap in the research
\end{abstract}

Diffusion of Innovation research has identified that personal characteristics of the adopter influence the likelihood of if and when an individual will adopt an innovation. Goldsmith and Hofacker (1991) found that domain specific innovativeness (DSI) is a useful predictor for consumers purchasing new products. This study extends the application of the DSI scale to the student decision of whether to enroll or not to enroll in a new major.

Two hundred and fifty-nine undergraduate business students enrolled in new and old majors were sampled in the study. Students completed a survey that included Goldsmith and Hofacker's (1991) six item DSI scale adapted to the domain of new majors. Exploratory factor analysis identified that three of the six DSI items constituted a unidimensional scale which is consistent with Grewal, et. al (2000). The resulting scale demonstrated strong psychometric properties suggesting that the three item scale is well suited for measuring student innovativeness. Study results suggest higher levels of DSI, math SAT score, and high school average for students selecting a new major. Gender and verbal SAT scores do not differ significantly between new majors and old majors. The results of the study are useful to administrators interested in launching a new major and to academic researchers' in understanding innovativeness in the context of students' course of study decisions.

\section{INTRODUCTION}

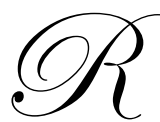

apid advances in technology and manufacturing have resulted in a plethora of new products. Though over 30,000 new products are introduced every year, it may not be enough. As Crain notes, "customers want an endless supply of new products" (2004, p. 12). Despite efforts to continually develop new products, "companies are finding it increasingly hard to maintain a unique advantage long enough to make good profits on an innovation" (Engardio and Keenan 2002, p. 94). Changes in technology affect services as well. Enhanced communication has enabled online education programs to grow and thrive. Colleges and universities have embraced this educational innovation as a way to meet needs of segments of students and provide flexibility in delivery of course content through methods such as online education. However, online education isn't the only innovation universities are offering. To keep pace with technological, information systems and communication changes, universities have also launched new majors to provide students with knowledge and skills in emerging career 
fields. Majors such as digital media arts and accounting information systems are but two new majors designed for the innovative student interested in emerging career fields.

Successful new majors must attract students to sustain the major and build a critical mass of students. Schools have often spent little time and effort on marketing new majors and targeting prospective students for the new major. It would be useful for schools to identify prospective students who are innovators, and more likely to enroll in new majors. Targeted communication with innovative high school seniors is critical because students increasingly have more choices in selecting universities and majors and appear to be better informed in making these choices.

The purpose of this research is to explore the characteristics of students who elect a major in a new field of study. We will first review the literature on innovativeness. We next describe the study we conducted and the results we obtained. Finally we discuss our findings and the implications they have for teaching and learning at colleges and universities.

\section{EDUCATION INNOVATION AND NEW MAJORS}

The education literature has focused on the role of faculty in developing new offerings, but has tended to ignore the role that students play in deciding to enroll in these new course and major field of study offerings. It has also not examined the characteristics of students as innovators who decide to assume the career related risks of enrolling in these new offerings, particularly new major offerings.

Unlike many other products and services that students consume, the choice to "consume" a new major requires a multi-year period of consumption. While durable goods are also consumed over a period of many years, a bad choice can often be corrected, especially if the product is under warranty. Services can be terminated. It is often easy for the consumer to learn whether the product or service is performing poorly soon after purchase.

This is a much more difficult process when choosing majors. When a student elects to major in a field, the student often can only estimate the package of knowledge content that will be provided during his tenure at the chosen school based primarily on the title of the major and any brief description provided in the college catalog. The high level of risk that the student bears in making such a choice is greater than the risk he would encounter in choosing to consume a new product. This greater risk arises primarily from uncertainty caused by the lack of complete "product" information he is able to obtain at the time of choice. Uncertainty is a key component of the adoption process (Gatignon and Robertson 1985). Faculty may change, courses may not be available, the job market may deteriorate, and a number of other things may happen. Having never "consumed" a major before, the students is in a learn-asyou-go mode whereby it may take three or four years or more plus post-graduation experiences to decide this was a bad choice. Yet the choice may have a more profound effect on students' futures than nearly any other decision the make. Given the high level of risk and uncertainty, why then would a student elect to register for a new major and what type of student would most likely pursue study of a new major?

Selecting a newly launched major is an involved process that provides a potentially risky decision for the student. Applying innovativeness theory from the consumer marketing area offers the opportunity to better understand some of the characteristics of students that would most likely sign up for a new major. The purpose of this study is to identify whether innovativeness theory is applicable to the new major decision and to determine new major student innovator characteristics.

\section{INNOVATIVENESS}

Adoption of innovations is a vast research area that has focused on topics such as the characteristics of the innovation, the rate of adoption, the influence of the social network, and the characteristics of the innovator (Rogers, 2003). All of these topics offer relevance to the field of education. For instance, new programs and majors should be designed so that they will be positively perceived and used by students. Understanding rates of adoption of educational innovations would enable administrators to better evaluate the status of new programs and methods and project future success of these innovations. Comprehending the innovator's social network and the influence of others 
on the decision to adopt innovations is useful for educators. Finally, being able to identify and attract innovators will increase the success rate of new educational programs and methods. Innovation in education often involves administrators, instructors, and students. The focus of this study is on the innovative student and his or her characteristics.

There is a paucity of research on student adoption of new majors so it is useful to look at the field of marketing and its study of consumers purchasing new goods and services for insights and direction. The inclination of an individual to purchase and try something new, be it a product, a service or an experience, has been studied with respect to a wide variety of products and services. Consumer innovation is "a predisposition to buy new and different products and brands rather than remain with previous choices and consumer patterns" (Steenkamp, Hofstede, \& Wedel, 1999). A distinction has been drawn between a general, innate state of innovativeness and a domain-specific state that manifests itself in a behavioral manner specific to some particular domain (Goldsmith and Hofacker 1991; Hirschman 1980; Midgeley and Dowling 1978). Domain-specific innovativeness (DSI) has been shown to be a strong predictor of a variety of measures including behavioral intentions and behavior itself (Agrawal and Prasad 1998; Citrin, et. al. 2000; Goldsmith 1998; Goldsmith, Flynn and Goldsmith 2003; Goldsmith and Flynn 1992; Goldsmith and Hofacker 1991). Furthermore, DSI has been shown to be a better predictor of consumer innovation than an individual's overall innate level of innovation (Roehrich, 2004). In this study we adapt the DSI scale of Goldsmith and Hofacker (1991) to the realm of student innovativeness with respect to enrollment in college offerings of new majors. Therefore we hypothesize that:

H1: Students who enroll in new majors will exhibit a higher level of DSI that students who enroll in older, more traditional majors.

Adoption of an innovation may also be influenced by innovator characteristics beyond DSI. For instance, the innovator should be able to understand the nature and benefits of an innovation. Accordingly, Rogers (2003), suggests that intelligence is positively associated with an individual's level of innovation. Furthermore considering the significant importance of intelligence in the educational process, it appears likely that a student's intelligence would influence adoption of educational innovations. Therefore we hypothesize that:

H2: Students who score higher on the DSI scale will have higher levels of intelligence than those who score lower on the DSI scale.

and,

H3: Students who enroll in new majors will have higher levels of intelligence than students who enroll in older, more traditional majors

\section{METHODOLOGY}

The study involved surveying 259 undergraduate business students enrolled in new and old majors at a private university located in the northeastern region of the United States. Men constituted $52.3 \%$ of the sample and women $47.7 \%$. The average age of the respondent was 20 years old. Recent new major offerings at this university include majors such as Digital Media Arts, Accounting Information Systems, and International Business. Students completed a survey that included Goldsmith and Hofacker's (1991) six item DSI scale adapted to the domain of new majors. Survey responses were matched with demographic information and academic records.

We measured personal innovator characteristics using our adaptation of the domain specific innovativeness (Goldsmith and Hofacker 1991). Goldsmith and others have adapted this scale to fit a variety of domains. Goldsmith and Hofacker (1991) provide evidence of unidimensionality of their six-item domain-specific innovativeness (DSI) scale. Most research applications of the DSI scale have found it to be unidimensional, but a few have not. These few studies have found that for some domains the scale is two dimensional, with the positive items loading on one dimension and the negative on the other (Goldsmith 2000; Goldsmith, Flynn and Goldsmith 2003; Grewal, et al 2000). Goldsmith, et. al. (2003) found that the two dimensions were correlated. When we performed exploratory 
common factor analysis with oblique rotation on the data we collected, however, we found that not only was our scale two-dimensional with the three positive-worded items loading on one factor while the three negative-worded items loaded on the second factor, but that the factors were not correlated $(r=0.025)$. It is not uncommon to find this characteristic in scales employing negatively-worded items (Herche and Engelland 1996). Goldsmith, et. al. (2003) handled the two-dimensional results by aggregating the scores of all six items to form a single DSI measure. Grewal, et. al. (2000), however, chose to ignore the negative items and only use the positive items. We follow Grewal, et. al. and use only the positive items in our analysis.

Initially statistical tests were used to determine the gender-specific characteristics of innovators versus noninnovators. Next data analysis consisting of an exploratory factor analysis to determine if the DSI scale when applied to the domain of major field of study was indeed unidimensional was applied. Unidimensional items were next tested for reliability using Cronbach's Alpha. Factor analysis was then used to compute factor scores for the unidimensional DSI factor. The factor scores were then used to test hypothesis H1, that is, for a relationship with the student choice to enroll or not enroll in a new major, a dichotomous variable, using a point-biserial correlation coefficient. Finally correlation analysis was used to test hypotheses $\mathrm{H} 2$ and $\mathrm{H} 3$.

\section{RESULTS}

As noted previously, the results of the common factor analysis using oblique rotation to achieve simple structure revealed that the DSI scale was two-dimensional when applied to the new major field of study domain. The two dimensions were not correlated, therefore only the three-positive-item scale was used in subsequent analysis (Grewal, et. al. 2000).

Reliability is defined as "the degree to which measures are free from error and therefore yield consistent results" (Peter, 1979, p. 6). This three-item DSI scale demonstrates strong reliability based on a Cronbach's Alpha of 0.824, (Table 1), more than satisfying Nunnally's criterion of 0.70 for reliability (1967).

Having ascertaining the strong reliability of the DSI scale, the influence of gender on the new major was also investigated. The breakdown of males and females in new majors is provided in Table $1 \mathrm{a}$.

Table 1a Crosstabulation of Gender with DSI

\begin{tabular}{|c|c|c|c|c|c|}
\hline & & & \multicolumn{2}{|c|}{ Enrolled as Primary or Secondary New Major } & \multirow[t]{2}{*}{ Total } \\
\hline & & & New Major & Old Major & \\
\hline \multirow[t]{4}{*}{ GENDER } & $\mathrm{F}$ & Count & 32 & 91 & 123 \\
\hline & & $\%$ within GENDER & $26.0 \%$ & $74.0 \%$ & $100.0 \%$ \\
\hline & $\mathrm{M}$ & Count & 35 & 100 & 135 \\
\hline & & $\%$ within GENDER & $25.9 \%$ & $74.1 \%$ & $100.0 \%$ \\
\hline \multirow{2}{*}{\multicolumn{2}{|c|}{ Total }} & Count & 67 & 191 & 258 \\
\hline & & $\%$ within GENDER & $26.0 \%$ & $74.0 \%$ & $100.0 \%$ \\
\hline
\end{tabular}

The chi-square test (Table 1b) for the crosstabulation in Table 1a shows that there is no significant difference between men and women in the decision to enroll in a new major. About $26 \%$ of all men and $26 \%$ of all women in our sample are enrolled in one of the new majors.

Table 1b Chi-Square Tests

\begin{tabular}{|l|c|c|c|}
\hline & Value & Df & Asymp. Sig. (2-sided) \\
\hline Pearson Chi-Square & $.000(*)$ & 1 & .987 \\
\hline N of Valid Cases & 258 & & \\
\hline
\end{tabular}


Next the relationship of DSI with selection of new major was investigated. The variable new major was coded 1 if a student was enrolled in a new major and 2 if enrolled in an old major. A higher value for the DSI factor score indicated more innovativeness on the part of the student. The point-biserial correlation indicated the DSI scale was significantly $(\mathrm{p}=0.000)$ correlated with the choice to enroll in a new major (Table 2$)$. The negative sign on the coefficient indicates that students enrolled in new majors were more domain-specifically innovative than students enrolled in old majors, thereby supporting hypothesis H1.

Table 2 Correlation of DSI with Major Enrollment

\begin{tabular}{|l|c|c|}
\hline Enrolled as Primary or Secondary New Major & Pearson Correlation & -.264 \\
\hline With & Sig. (2-tailed) & .000 \\
\hline DSI Positive Factor & $\mathrm{N}$ & 256 \\
\hline
\end{tabular}

Next a set of correlations (Table 3) were run between the DSI scores and the SAT Verbal and Math scores and high school grade point averages. Results indicate that domain-specific innovativeness was weakly related to high school grade point averages (.16 correlation, $\mathrm{p}=0.013)$, but not to SAT Verbal $(\mathrm{p}=0.136)$ or SAT Math $(\mathrm{p}=$ 0.12 ) scores. The positive sign indicate that more innovative students tended to be more intelligent when intelligence was evaluated using high school grade point averages, thereby supporting hypothesis H2. More innovative students, however, did not score significantly higher or lower on SAT verbal or math tests.

Table 3 Pearson Correlations between DSI score and SAT Verbal and Math and HS GPAs

\begin{tabular}{|l|c|c|c|c|}
\hline & & SATV & SATM & HSAVG \\
\hline DSI Positive Factor & Pearson Correlation & .097 & .101 & .158 \\
\hline & Sig. (2-tailed) & .136 & .120 & .013 \\
\hline & N & 238 & 238 & 248 \\
\hline
\end{tabular}

Finally the relationship between intelligence (academic performance) and selection of a new major was analyzed through independent t-tests. Proxies of intelligence -- verbal and math SAT scores, and academic performance, high school average -- were utilized. The means of new and old majors for these measures are listed in Table $4 \mathrm{a}$ and results of independent t-tests are shown in Table $4 \mathrm{~b}$. This analysis reveals that students enrolled in a new major have significantly $(\mathrm{p}=0.043)$ higher SAT Math scores $\left(\right.$ mean $_{\text {new }}=585$; men $\left._{\text {old }}=563\right)$ and significantly higher $(\mathrm{p}=0.004)$ high school grade point averages $\left(\operatorname{mean}_{\text {new }}=92 ;\right.$ mean $\left._{\text {old }}=89\right)$ thereby supporting hypothesis H3. Students enrolled in a new major, however, do not significantly differ $(\mathrm{p}=0.192)$ from students enrolled in old majors with respect to SAT verbal test scores $\left(\right.$ mean $_{\text {new }}=544 ;$ mean $\left._{\text {old }}=530\right)$.

Table 3a Group Statistics

\begin{tabular}{|l|l|c|c|}
\hline & Enrolled as Primary or Secondary New Major & N & Mean \\
\hline SAT Verbal & New Major & 62 & 544.35 \\
\hline & Old Major & 179 & 530.00 \\
\hline SAT Math & New Major & 62 & 585.16 \\
\hline & Old Major & 179 & 563.35 \\
\hline High School & New Major & 63 & 91.0502 \\
\hline Grade Average & Old Major & 188 & 88.8047 \\
\hline
\end{tabular}


Table 3b Independent Samples Test* t-test for Equality of Means

\begin{tabular}{|l|c|c|c|c|c|}
\hline & F & Sig. & t & df & Sig. (2-tailed) \\
\hline SAT Verbal Equal variances assumed & .005 & .944 & 1.310 & 239 & .192 \\
\hline SAT Math Equal variances assumed & .035 & .852 & 2.035 & 239 & .043 \\
\hline High School Grade Average Equal variances not assumed & 6.214 & .013 & 2.945 & 123.640 & .004 \\
\hline * Levene's Test for Equality of Variances
\end{tabular}

* Levene's Test for Equality of Variances

\section{DISCUSSION AND CONCLUSION}

Study results suggest that Domain Specific Innovation applies to the new major decision and that student characteristics are related to enrollment into a new major. The strong psychometric properties, e.g. high internal reliability, of the three item DSI scale indicate that this measure is well suited for educational innovations. Using this scale with high school students would provide an efficient method to identify the most likely candidates for new academic programs. The study provided evidence of the importance of academic performance, academic aptitude, and gender on enrollment in a new major.

The findings that above average performing students are attracted to innovative new majors provide both a challenge and an opportunity to academic institutions. The opportunity results from the advantage that colleges and universities have in attracting brighter and more intelligent students. In doing so, colleges and universities have the ability to trade-up their major offerings thereby increasing demand as well as selectivity in accepting students. This selectivity facilitates both more prestige and higher tuition income for the institution along with more consistent levels of student enrollment over time. The challenge lies in the ability of faculty to improve themselves so as to be able to effectively develop the new course offerings which the new major demands as well as improve the level of their course to meet the higher levels of academic ability in students who enroll in these new majors. The institution must support these efforts by providing the promotional and recruiting support needed to attract the higher quality students to these new majors and by enhancing the ability of students enrolled in these new majors to obtain and hold the jobs in the associated career fields.

The finding that the SAT math scores are significantly related to the decision to enroll in a new major but not to innovativeness (DSI) owes to the fact that the DSI score does not map 1:1 onto the decision to enroll in a new major. Though more innovative students tend to score higher on both SAT verbal and math tests, the differences were not significant. The higher scores on SAT math for students enrolled in new majors may be explained by the quantitative nature of the major in which they were enrolled. A more quantitatively oriented major would naturally attract students with higher SAT math scores. Accounting Information Systems may be perceived to be more quantitatively oriented than say marketing or management majors.

The finding that men and women were not different in terms of the decision to enroll in a new major is comforting. There is not reason to expect that a woman would be more or less likely to enroll in a new major than a man, unless it specifically pertained to women, such as a women's studies major, or vice versa.

The finding of a relationship between DSI and the decision to enroll in a new major extends the applicability of the DSI scale to a previously untested domain. The different characteristics of the market for new majors, the length of time needed to consume the "product", the risk taken in enrolling in the new major, and the characteristics of students as both consumers and innovators in this education market make for quite noticeable differences that could influence the applicability of the DSI scale to this domain.

This study has extended previous research by applying DSI to the area of education. Accordingly, this study provides a foundation for further research in this area. This research could be extended by investigating the relationship of the innovator with other aspects of the innovation process such as characteristics of the innovation, the influence of the innovator's social network, and rate of adoption of the innovation. For instance, the importance of innovator's characteristics may change with the attributes of the educational innovation. With this knowledge 
educators could tailor innovations to match the innovation level of the targeted educational group. Also, understanding the influence of others (e.g., peers, parents, teachers, and counselors) in the student's enrollment decision is important to the marketing and communication of a new major. Finally, investigating the level of innovation and the rate at which an innovation is adopted, would help educators to understand whether the new major will attract the necessary critical mass to succeed in the long run.

Many educators demonstrate a steadfast determination and strong ability to deliver innovative programs and teaching methods. Still some of these programs fail due to lack of student interest. Focusing on the innovative student characteristics offers the potential to develop communication strategies aimed at student innovators that offer the potential of enhancing the success rate of educational innovations.

\section{REFERENCES}

1. Agrawal, Ritu and Jayesh Prasad. (1998). "A Conceptual and Operational Definition of Personal Innovativeness in the Domain of Information Technology.” Information Systems Research. 9(2) (June), 204215.

2. Cutrin, A. V., D. E. Sprott, S. N. Silverman, and D. E. J. Stern, (2000). “Adoption of Internet Shopping: The Role of Consumer Innovativeness". Industrial Management and Data Systems, 100(7), 294-300.

3. Crain, Keith. (2004). "New Products Just Keep Coming.” Detroit: Automotive News (Oct 11), 79(6116), 12.

4. Engardio, Pete and Faith Keenan. (2002). "The Copycat Economy Once, a hot new idea spelled years of fat profits. But these days, rivals are moving into markets before you can say 'clone." New York: Business Week. (August 26) (3796), 94.

5. Gatignon, Hubert and Thomas S. Robertson. (1985). “A Propositional Inventory for New Diffusion Research.” Journal of Consumer Research. 11(March) 849-867.

6. Goldsmith, Ronald E. (1990). "The Validity of a Scale to Measure Global Innovativeness.” Journal of Applied Business Research. 7, 89-97.

7. Goldsmith, Ronald E. (1998). "Some Characteristics of Wine Innovators". International Journal of Wine Marketing. 10(1), 5-12.

8. Goldsmith, Ronald E. (2000). "Effects of Direction-of-Item Wording on Scale Psychometrics." In Marketing Advances in the New Millennium, Dawn R. Deeter-Schmeltz and Timothy P. Hartman, eds. Society for Marketing Advances, Athens, OH, 134-139.

9. Goldsmith, Ronald E. (2001). "Using the Domain Specific Innovativeness Scale to Identify Innovative Internet Consumers". Internet Research: Electronic Networking Applications and Policy. 11(2), 149-158.

10. Goldsmith, Ronald E. and Leisa R. Flynn. (1992). "Identifying Innovators in Consumer Product Markets." European Journal of Marketing. 26 (12), 42-55.

11. Goldsmith, Ronald E., Leisa R. Flynn and Elizabeth B. Goldsmith. (2003). "Innovative Consumers and Market Mavens." Journal of Marketing Theory and Practice. 11 (4) (Fall), 54-65.

12. Goldsmith, Ronald E. and Charles F. Hofacker. (1991). "Measuring Consumer Innovativeness." Journal of the Academy of Marketing Science. 19 (Summer), 1004-1116.

13. Grewal, Rajdeep, Raj Mehta and Frank R. Kardes. (2000). "The Role of the Social-identity Function of Attitudes in Consumer Innovativeness and Opinion Leadership.” Journal of Economic Psychology. 21. 233252.

14. Herche, Joel \& Brian Engelland. (1996). "Reversed-polarity Items and Scale Unidimensionality," Journal of the Academy of Marketing Science. 24 (4) (Fall), 366-374.

15. Hirschman, Elizabeth C. (1980). "Innovativeness, Novelty-Seeking, and Consumer Creativity." Journal of Consumer Research. 7 (December) 283-295.

16. Midgeley, David F. and Grahame R. Dowling. (1978). "Innovativeness: The Concept and Its Measurement," The Journal of Consumer Research. 19 (4) March, 611-625.

17. Nunnally, Jum C. (1967). Psychometric Theory. New York: McGraw-Hill.

18. Peter, J. P. (1979). "Reliability: A Review of Psychometric Basics and Recent Marketing Practices". Marketing Research, 16, 6-17.

19. Roehrich, G. (2004). "Consumer Innovativeness: Concepts and Measurements”. Journal of Business Research, 57, 671-677. 
20. Rogers, E. M. (2003). Diffusion of Innovations (5th ed.). New York, New York: Free Press.

\section{NOTES}

